\section{Suitability of Different Gels as Seed Carriers and Germination and Emergence Promoters in Processing Carrots}

\author{
Rowan D. Briscoe, Rajasekaran R. Lada, ${ }^{1}$ and Claude D. Caldwell \\ Department of Plant and Animal Science, Nova Scotia agricultural College, \\ Truro, Nova Scotia, Canada B2N 5E3
}

\author{
Kevin Sibley \\ Department of Engineering, Nova Scotia agricultural College, Truro, Nova \\ Scotia, Canada B2N 5E3
}

Additional index words. agar, algenic acid, artificial exosperm, guar gum, Laponite RD, Laponite RDS, preconditioning, processing carrot, rate of germination, temperature, vigor value

\begin{abstract}
Stand establishment is critical for optimizing yield and quality in carrots. Low soil temperatures and moisture conditions often challenge seed germination and emergence. Providing an artificial exosperm with appropriate germination promoters, stress conditioners and growth invigorators to the seed may facilitate uniform germination and emergence. Germination patterns and velocity of germination of 'Oranza' carrot was studied. Seeds were mixed in different types of gels at various ratios and incubated at either 5 or $20^{\circ} \mathrm{C}$. Gels used were Laponite RD, Laponite RDS, guar gum, algenic acid, and agar. Data on germination percentage was collected and the velocity of germination was calculated. Germination was delayed at $5{ }^{\circ} \mathrm{C}$. Both at 5 and $20^{\circ} \mathrm{C}$, Laponite RD promoted and enhanced germination and vigor, and resulted in the highest mean germination percentage $\left(90 \%\right.$ at $20{ }^{\circ} \mathrm{C}$ and $89 \%$ at $5{ }^{\circ} \mathrm{C}$ ). Laponite $\mathrm{RD}$ at $2.5 \%$ has shown an overall advantage in germination percentage $\left(94 \%\right.$ at $20{ }^{\circ} \mathrm{C}$ and $87 \%$ at $\left.5^{\circ} \mathrm{C}\right)$ over other gel types and concentrations.
\end{abstract}

To identify an appropriate method to deliver the GEPs, 1) the seeds were either preconditioned using $\mathrm{GA}_{3}$ at $100 \mathrm{mg} \cdot \mathrm{L}^{-1}$ or 2) $\mathrm{GA}_{3} 100$ $\mathrm{mg} \cdot \mathrm{L}^{-1}$ was incorporated in Laponite $\mathrm{RD}$ gel and the seeds were incubated either at 5 or 20 ${ }^{\circ} \mathrm{C}$. At $20^{\circ} \mathrm{C}$, carrot seeds preconditioned with $\mathrm{GA}_{3}$ have shown a significant enhancement in germination percentage within the first five days after seeding. Low temperature reduced germination in the controls at $5^{\circ} \mathrm{C}$. However, the seeds preconditioned with $\mathrm{GA}_{3}$ have shown a significant enhancement in germination percentage over $\mathrm{GA}_{3}$ impregnated in the gel. $\mathrm{GA}_{3}$ preconditioning can help to promote germination and emergence under limiting low temperatures and low moisture conditions. This could be chosen to provide a possible protective delivery system and could serve as an articifial exosperm for carrots. This will aid in developing a synergistic approach for stand establishment for carrot production.

Establishing an optimal crop stand is imperative for optimizing yield and quality in carrots, especially, when they are grown under low soil

Received for publication 29 Dec. 2005. Accepted for publication $17 \mathrm{Feb}$. 2006. This paper is portion of a graduate thesis submitted by R.D. Briscoe. The authors thank the funding provided for this study by Nova Scotia Department of Agriculture and Fisheries, Technology Development 2000 program, Oxford Frozen Foods Limited and Bragg Lumber Company Limited. Authors also wish to thank the research staff of Processing Carrot Research Program.

${ }^{1}$ To whom reprint request should be addressed; emailrlada@nsac.ca. temperatures and rainfed conditions. Providing an artificial exosperm using gels impregnated with appropriate germination and emergence promoters (GEPs), stress conditioners and growth invigorators or preconditioning seeds with these same chemicals, may facilitate uniform germination and emergence. This may provide a solution for establishing optimal crop stand with enhanced seedling vigor. There is, however, only limited information available and the stand establishment technology needs to be developed. Also, in order for seeds to get the full benefit of potential GEPs, seed preconditioning technology was explored. Seed preconditioning by hardening (alternate wetting and drying), chitting (pregermination), osmoconditioning (priming) using polyethylene glycol, matriconditioning, have all been used to promote germination with varied success (Khan, 1992). Seed preconditioning is a technique used to promote drought and temperature acclimation in seeds (Rajasekaran et al., 2002). Seed preconditioning changes the physiological characteristics of seeds, increasing their ability to tolerate drought and temperature stress (Rajasekaran and Blake, 2002). Seed preconditioning using plant growth regulators; for example, $\mathrm{GA}_{3}$ and benzyl adenine (BA) and salts such as potassium nitrate, phosphate and chloride have been reported to promote germination of carrot seeds (Cantliffe et al., 1987). There is however only limited information on the suitability of seed preconditioning agents in promoting and hastening germination and vigor under low temperature available. Also, for developing an integrated approach using a gel as a carrier (artificial exosperm) and to provide a total protective delivery system for processing carrots, it is critical to identify the suitable method(s) of introducing GEPs in order to seeds to get the full benefit. With this in mind, experiments were conducted with the objectives to, 1) identify suitable gel(s) and the optimum gel concentration that will promote germination at both 5 and $20^{\circ} \mathrm{C}$, and 2) determine an effective delivery system for germination and emergence promoters (GEPs).

\section{Materials and Methods}

Screening gel types for their suitability as seed carriers. Various gels were obtained and evaluated for their suitability as seed carriers. These included a synthetic clay gel, Laponite $\mathrm{RD}$, a synthetic clay gel, Laponite RDS (Southern Clay Products, Inc., Texas), guar gum (EL Peto Products, Kitchener, Ont., Canada), sodium alginate (ALDRICH Chemical Co. Inc., Milwaukee, Wis.) and agar (DIFCO Laboratories Detroit, Mich.). Carrot (Daucus carota L var. sativus) seeds of cv. Oranza, a high yielding slicervariety, were obtained from Bejo Seed Co., New York. This experiment was a three factor factorial (gel, concentration and temperature) randomized complete block design (RCBD). It was blocked by growth chamber due to two different temperature regimes. The data was analyzed using repeated measures analysis. The treatment factors and their levels are shown below. Gel forming compounds were mixed in distilled water to deliver various concentrations which were dispensed into sterile petri dishes $(100 \times 15 \mathrm{~mm})$. Each petri dish contained $25 \mathrm{~mL}$ of gel. Seeds of uniform size (1.6 to $1.8 \mathrm{~mm}$ ) were counted and submerged into the gels. Seeds were also placed on Munktell's No.1 F filter paper in sterile petri dishes moistened with distilled water which served as the control. One hundred seeds were used for each treatment under each replication. Each treatment was replicated four times. The petri dishes were incubated at 5 and $20^{\circ} \mathrm{C}$ until germination was complete.

Factor 1: Temperature. Levels used were 5 and $20^{\circ} \mathrm{C}$.

Factor 2: Gel types. Levels used were 1) control (seeds placed on Munktell's No. 1 F filter paper in sterile petri dishes moistened with distilled water), 2) agar, 3) Laponite RDS, 4) Laponite $\mathrm{RD}, 5)$ guar gum, and 6) algenic acid

Factor 3: Concentration. Five levels were used (depending on gel type) as follows: 1) agar at $0.3 \%, 0.35 \%, 0.4 \%, 0.45 \%$, and $0.5 \%(\mathrm{w} / \mathrm{v})$; 2) Laponite RDS at $10 \%, 12 \%, 14 \%, 15 \%$, and $16 \%(\mathrm{w} / \mathrm{v}) ; 3$ ) Laponite RD at 2.5\%, $2.75 \%$, $3.0 \%, 3.25 \%$, and $3.5 \%(\mathrm{w} / \mathrm{v}), 4)$ guar gum at $0.5 \%, 0.75 \%, 1.0 \%, 1.25 \%$, and $1.5 \%(\mathrm{w} / \mathrm{v})$; and 5) algenic acid at $2.0 \%, 2.25 \%, 2.5 \%, 2.75 \%$, and $3.0 \%(\mathrm{w} / \mathrm{v})$.

Standardization of germination and emergence promoters (GEPS) delivery system. This study was conducted as a two factor factorial experiment. Factor 1 represented the application method (GA-preconditioning; GA-gel incorporation) and factor 2 included the temperature regimes $\left(5\right.$ and $\left.20^{\circ} \mathrm{C}\right)$. This experiment adopted a randomized complete block design 
(RCBD) and was blocked by growth chamber. The gel, Laponite RD, was chosen as a carrier. Gibberellic acid $\left(\mathrm{GA}_{3}\right)$ obtained from Sigma, Canada, was prepared at a concentration of $100 \mathrm{mg} \cdot \mathrm{L}^{-1}$ in distilled water and it was used as a seed preconditioning agent as described in Rajasekaran et al. (2004). 'Oranza' carrot seeds were weighed and placed in $250 \mathrm{~mL}$ Erlenmeyer flasks in $\mathrm{GA}_{3}$ solutions at a ratio of $1 \mathrm{~g}$ seeds: 10 $\mathrm{mL}$. The flasks containing seeds and $\mathrm{GA}_{3}$ were sealed with Parafilm and these were allowed to precondition for $24 \mathrm{~h}$ at a temperature of 23 $\pm 1{ }^{\circ} \mathrm{C}$ in an environmental incubation shaker set at $147 \mathrm{rpm}$. After $24 \mathrm{~h}$, the excess solution was decanted. The seeds were then rinsed using distilled water, blotted dry and allowed to air dry at room temperature for $12 \mathrm{~h}$. Laponite RD of $2.5 \%(\mathrm{w} / \mathrm{v})$ was prepared and dispensed into sterile petri dishes $(100 \times 15 \mathrm{~mm})$. In total, $25 \mathrm{~mL}$ of gel were dispensed into each petri dish. Then, GA-preconditioned seeds were submerged into Laponite RD gel and the untreated seeds were applied into Laponite RD mixed with GA. GA-preconditioned and nonpreconditioned seeds were placed on Munktell's No. 1F filterpaper in sterile pertidishes which served as the controls. Filter papers were moistened using distilled water continuously until germination was completed. The seeds in the petri dishes were incubated at 5 or $20^{\circ} \mathrm{C}$. Each treatment was replicated four times. The following is the summary of the treatments:

Factor 1: Temperature: Two temperatures were used $\left(5\right.$ and $\left.20^{\circ} \mathrm{C}\right)$.

Factor 2: Application methods: Five methods were used (including control): T1: 100 seeds preconditioned using $\mathrm{GA}_{3}$ at 100 $\mathrm{mg} \cdot \mathrm{L}^{-1}$ impregnated in Laponite $\mathrm{RD}$ gel; $\mathrm{T} 2$ : 100 nonpreconditioned seeds impregnated in Laponite RD gel mixed with $\mathrm{GA}_{3}$ at $100 \mathrm{mg} \cdot \mathrm{L}^{-1}$; T3: 100 nonpreconditioned seeds impregnated in Laponite RD gel only; T4: control (100 nonpreconditioned seeds placed on Munktell's No. $1 \mathrm{~F}$ filter paper in sterile petri dishes moistened with distilled water; and T5: 100 seeds preconditioned with $\mathrm{GA}_{3}$ at $100 \mathrm{mg} \cdot \mathrm{L}^{-1}$ placed on Munktell's No. $1 \mathrm{~F}$ filter paper in sterile petri dishes moistened with distilled water.

Germination and vigor value. Germination and vigor were monitored. Germination was considered to be complete when the radicle visibly extended beyond the surface of the seed usually protruding through a fracture in the seed coat (Rajasekaran et al., 2002). The number of seeds germinated each day was counted and the germination percentage was calculated. Germination vigor (Czabator, 1962) was modified to include the number of days of incubation at each temperature and each treatment and used since it combines both germination speed and germination energy. The germination vigor $(\mathrm{V})$ was calculated as follow: $\mathrm{V}=(\mathrm{a} / 1+\mathrm{b} / 2+\mathrm{c} / 3$ $+\mathrm{d} / 4 \ldots . . x / \mathrm{n}) \mathrm{S} \times 100$, where, $\mathrm{a}, \mathrm{b}, \mathrm{c}, \mathrm{d}$ and $\mathrm{x}$ represent the number of seeds germinated after the first, second, third, fourth and $n$th days of incubation, respectively, and $\mathrm{S}$ represents the total number of seed in the sample.

Statistical analysis. The GLM procedure with repeated measures analysis (SAS Institute Inc., Cary, N.C.) was used. ANOVA was used to test interactions among the factors and statistical significance of the components of the design. Means were separated using Fisher's protected LSD $(P<0.05)$ when $\mathrm{F}$ tests were determined to be significant.

Screening gel types for their suitability as seed carriers. Analysis of variance (ANOVA)

Table 1. ANOVA for the screening of gel types for their suitability as seed carriers. Three-way interaction (treatment $\times$ concentration $\times$ temperature) for promotion of germination and vigor at both 5 and 20 ${ }^{\circ} \mathrm{C}$.

\begin{tabular}{lrrrr}
\hline Source & DF & \multicolumn{1}{c}{ MS } & \multicolumn{1}{c}{ F } & $P$ \\
\hline GEP & 5 & 205656.545 & 500.26 & $<0.0001$ \\
Temperature & 1 & 1609476.253 & 3915.04 & $<0.0001$ \\
GEP $\times$ temperature & 5 & 102583.645 & 249.53 & $<0.0001$ \\
Concentration & 18 & 5239.323 & 12.74 & $<0.0001$ \\
GEP $\times$ concentration & 2 & 515.056 & 1.25 & 0.2858 \\
Temperature $\times$ concentration & 18 & 5313.439 & 12.92 & $<0.0001$ \\
GEP $\times$ temperature $\times$ concentration & 2 & 288.895 & 0.70 & 0.4953 \\
Error & 3276 & 411.100 & & \\
\hline
\end{tabular}
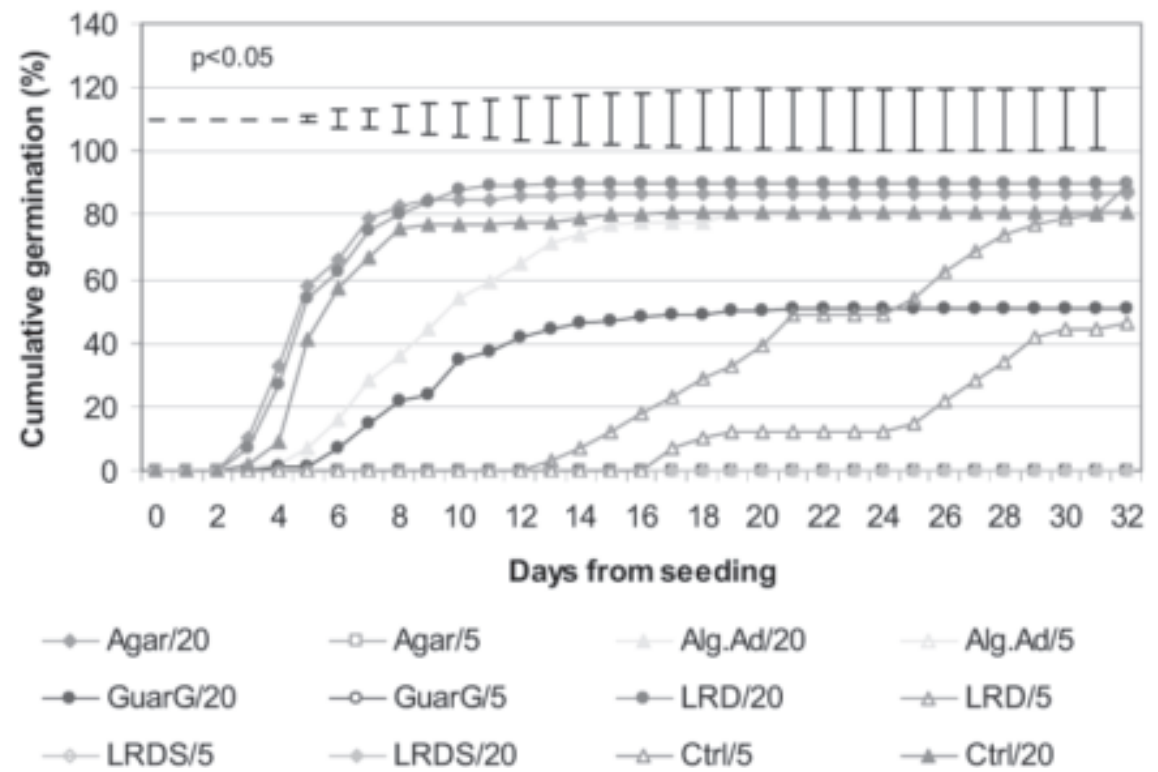

Fig. 1. Cumulative germination of 'Oranza' carrot (Daucus carota L var. sativus) as influenced by Laponite $\mathrm{RD}$, Laponite RDS, agar, algenic acid, and guar gum incubated under contrasting temperatures of 5 and $20^{\circ} \mathrm{C}$. Open symbol represents $5{ }^{\circ} \mathrm{C}$; closed symbol represents $20{ }^{\circ} \mathrm{C}$. Bars represent LSD at $P$ $<0.05$. LRDS = Laponite RDS; Ctrl = control; LRD = Laponite RD; GuarG = guar gum; Alg.Ad = algenic acid.

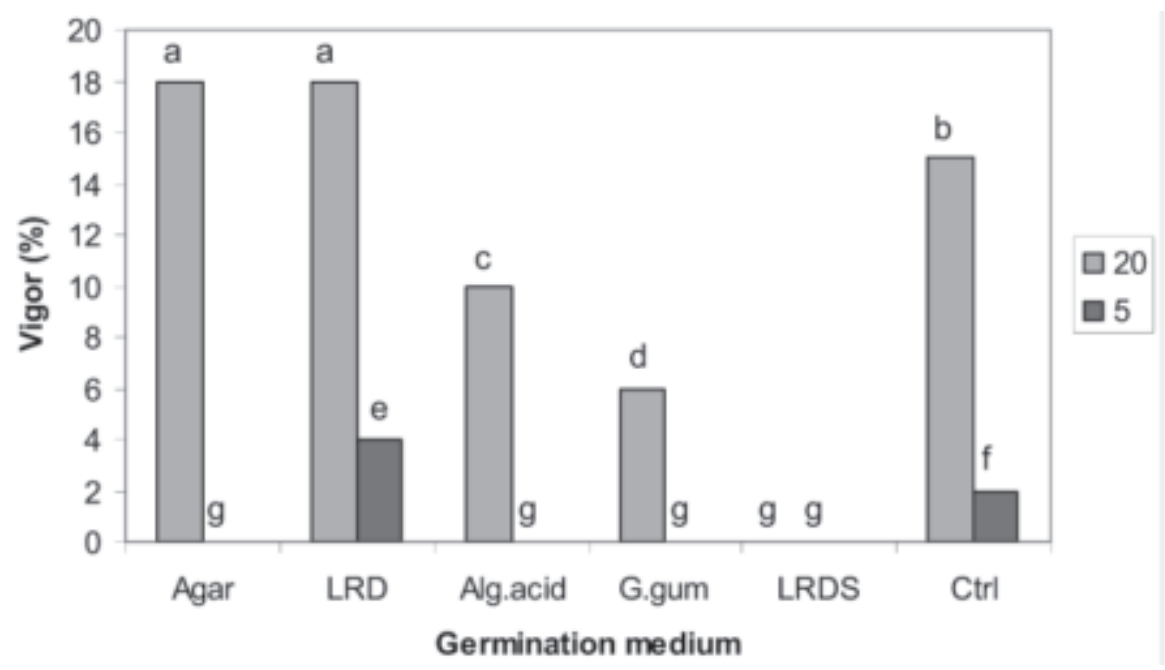

Fig. 2. Vigor value of 'Oranza' carrot (Daucus carota L var. sativus) as influenced by Laponite RD, Laponite RDS, agar, algenic acid, and guar gum incubated under contrasting temperatures of 5 and $20^{\circ} \mathrm{C}$. Letters that are the same indicate that there is no significant different among the treatments $(P<0.05)$. LRDS = Laponite RDS; Ctrl = control; LRD = Laponite RD; GuarG = guar gum; Alg.Ad = algenic acid. Absences of bars mean values were zero (0). 
(Table 1) showed that there was not a significant three-way interaction (treatment $\times$ concentration $\mathrm{x}$ temperature) for germination and vigor. However, a significant two-way interaction $(P$ $<0.0001$ ) was detected between treatments and temperatures.

Both germination and vigor value were significantly affected by temperature. Germination (Fig. 1) and vigor (Fig. 2) were significantly lower at $5{ }^{\circ} \mathrm{C}$ compared to $20^{\circ} \mathrm{C}$. Germination delayed until day 32 at $5^{\circ} \mathrm{C}$, except in Laponite $\mathrm{RD}$, while germination occurred on the fourth day at $20^{\circ} \mathrm{C}$. At $20^{\circ} \mathrm{C}$, there was no difference in germination and vigor between agar and Laponite RD gels. However, both these gels promoted germination and vigor significantly $(P<0.05)$ compared to the control, guar gum, Laponite RDS, and algenic acid (Figs. 1 and 2). Guar gum inhibited germination and vigor at $20^{\circ} \mathrm{C}$. At $20^{\circ} \mathrm{C}$, although germination began on day 3 (Laponite RD, agar, algenic acid and the control) or day 4 (guar gum), germination completed on different days depending on the gel type. Germination completed on day 13 (Laponite RD), 14 (agar), 17 (algenic acid), 19 (control) or day 21 (guar gum).

Gels behaved differently at different temperatures. At $20^{\circ} \mathrm{C}$, Laponite RD registered the highest mean germination percentage of $90 \%$ while it was $87 \%$ with Agar, $80 \%$ with Algenic acid and $51 \%$ with Guar gum (Fig. 3). At $5{ }^{\circ} \mathrm{C}$ however, the highestmean germination percentage was with Laponite RD (89\%) compared to $46 \%$ for the control (Fig. 3). While Laponite RD hastened germination and vigor both at 5 and 20 ${ }^{\circ} \mathrm{C}$ (Figs. 1 and 2), agar hastened germination only at $20^{\circ} \mathrm{C}$.

Even though there was no significant interaction between gel and concentrations, at 20 ${ }^{\circ} \mathrm{C}$, Laponite RD 2.5\% recorded the highest germination percentage compared to the other concentrations or the control (Fig. 3). At $5{ }^{\circ} \mathrm{C}$ however, there was no significant difference in germination percentage among any of the concentrations (Fig. 4).

Standardization of GEP delivery system. ANOVA showed that germination percentage and vigor value were significantly affected both by temperature and application methods (treatments). A significant interaction $(P<$ $0.0001)$ between these two factors was also observed (Table 2) indicating that the application methods had different relative effects on germination percentage and vigor depending on the temperature.

In general, as with the other experiment, low temperature $\left(5^{\circ} \mathrm{C}\right)$ reduced germination and vigor significantly compared to $20{ }^{\circ} \mathrm{C}$ (Fig. 5). At $20^{\circ} \mathrm{C}$, the control treatment seeds germinated on day 4 while the seeds incubated at $5{ }^{\circ} \mathrm{C}$ germinated on day 22 (Fig. 5). Preconditioning seeds using $\mathrm{GA}_{3}$ however, enhanced germination and vigor both at 20 and $5{ }^{\circ} \mathrm{C}$ (Figs. 5 and 6 ). At $20^{\circ} \mathrm{C}$, for seeds preconditioned with $\mathrm{GA}_{3}$, germination and vigor was enhanced significantly $(P<0.05)$ compared to the control or the ones where GA was supplied to the gel (Figs. 5 and 6). While germination and vigor were significantly reduced at $5{ }^{\circ} \mathrm{C}$, the GA preconditioned seeds germinated much earlier (day 13) compared to the controls (day 23).
Although low temperature delayed germination and reduced vigor, GA preconditioning led to faster germination compared to the controls, reaching the highest germination percentage in 6 d. By day 18, the germination percentage of the GA preconditioned seeds in Laponite RD remained similar to that of those incubated at $20^{\circ} \mathrm{C}$. Germination in the controls at $5^{\circ} \mathrm{C}$ was the slowest. Seeds did not germinate until day 22 , reaching only $20 \%$ or lower on the final day of observation (Fig. 5). Although the GA preconditioned seeds in Gel performed better than the GA preconditioned seeds in filter paper at $5^{\circ} \mathrm{C}$ to start with, germination percentage was

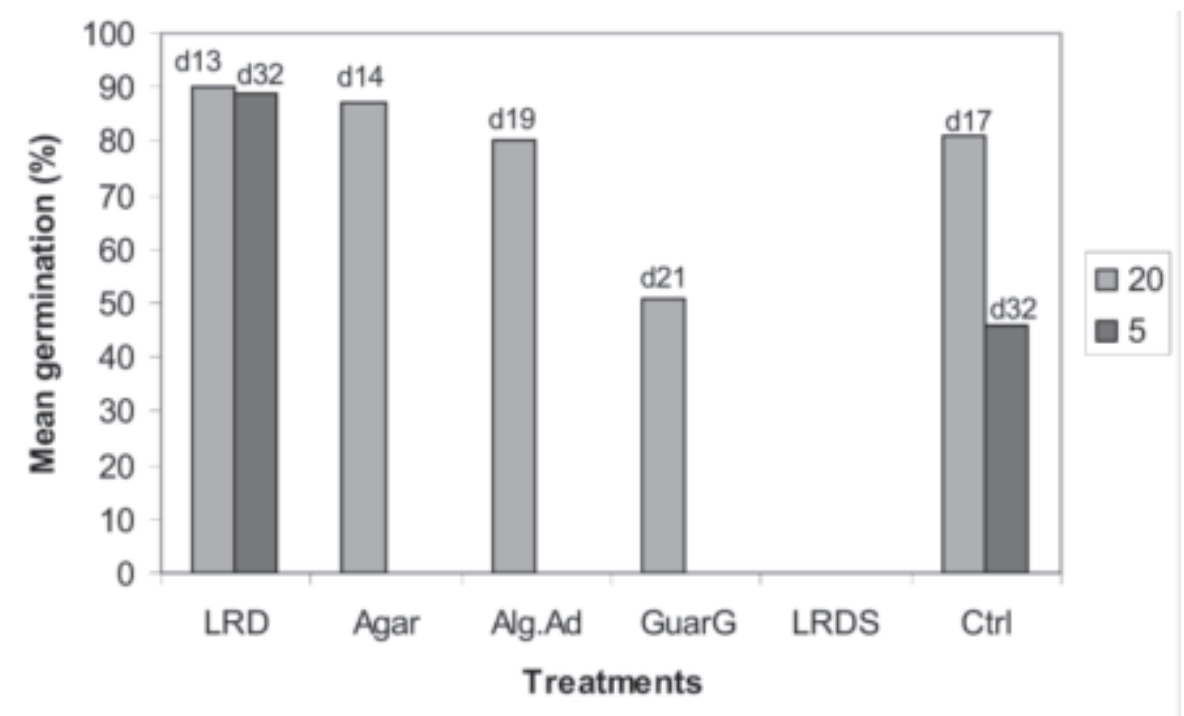

Fig. 3. The highest mean germination percentage observed in 'Oranza' carrot seeds as influence by Laponite $\mathrm{RD}$, Laponite RDS, agar, algenic acid, and guar gum incubated under contrasting temperatures of 5 and $20^{\circ} \mathrm{C}$. Day 13, day 14 , day 17 , day 19 , day 21 , and day 32 represents the days taken for reaching the highest mean germination percentage. Data obtained from Fig. 1. Absences of bars mean values were zero (0).
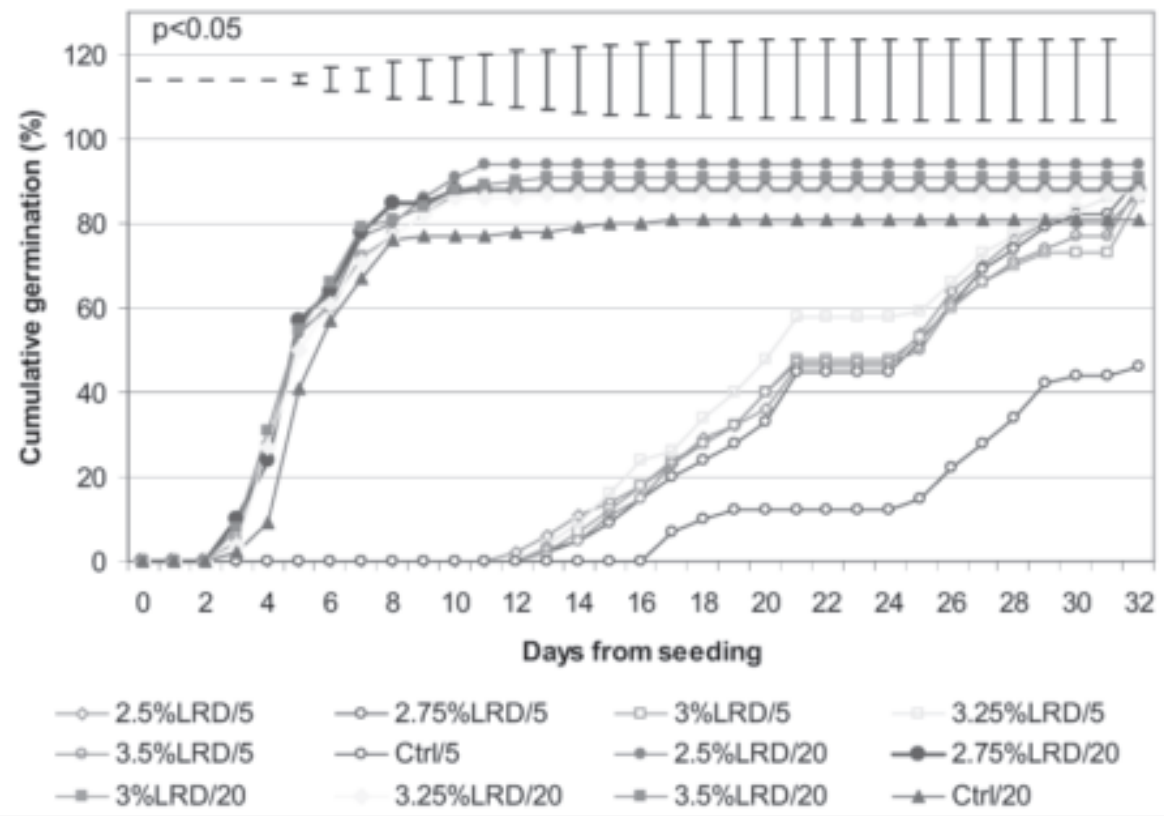

Fig. 4. Cumulative germination of 'Oranza' carrot (Daucus carota L var. sativus) as influenced by Laponite RD mixed at different concentrations and incubated at 5 and $20^{\circ} \mathrm{C}$. Bars represent LSD at $P<0.05$. Open symbol represents $5{ }^{\circ} \mathrm{C}$; closed symbol represents $20^{\circ} \mathrm{C}$; $\mathrm{Ctrl}=$ control; LRD $=$ Laponite RD.

Table 2. ANOVA for the standardization of GEP delivery system. Two-way interaction, 1) Application method - (GA-preconditioning; GA-Gel incorporation) and factor 2 included the temperature regimes $\left(5\right.$ and $\left.20^{\circ} \mathrm{C}\right)$.

\begin{tabular}{lrrrc}
\hline Source & DF & MS & F & $P$ \\
\hline GEP & 3 & 21568.9517 & 31.70 & $<0.0001$ \\
Temperature & 1 & 631126.1250 & 927.52 & $<0.0001$ \\
GEP $\times$ temperature & 3 & 9792.6183 & 14.39 & $<0.0001$ \\
Error & 792 & 680.446 & & \\
\hline
\end{tabular}


similar on the final day of observation. Germination percentage did not differ significantly among the GA preconditioned seeds incubated at $5{ }^{\circ} \mathrm{C}$ or the ones at $20^{\circ} \mathrm{C}$ on the final day of observation. In conclusion, applying GA as a preconditioning treatment was the mosteffective technique compared to GA applied to gel.

Vigor value was also reduced significantly at $5{ }^{\circ} \mathrm{C}$ compared to $20^{\circ} \mathrm{C}$. The reduction was nearly $10 \%$ compared to control or Gel $+\mathrm{GA}-0$ or $\mathrm{Gel}+\mathrm{GA}$. However, seeds preconditioned with GA showed a significant advantage compared to the untreated controls or to the ones where GA was applied to the gel both at 20 and $5{ }^{\circ} \mathrm{C}$ (Fig. 6).

Figure 7 indicates that it took $11 \mathrm{~d}$ for completion of germination with seeds under control incubated at $20^{\circ} \mathrm{C}$ while it took $25 \mathrm{~d}$ to reach $35 \%$ at $5{ }^{\circ} \mathrm{C}$. However, preconditioning using GA hastened germination. The highest mean germination was observed on day 8 while it started on day 11 in the control. Preconditioning using GAenhanced germination percentage and reached the highest germination of $85 \%$ on day 23. This response was similar for the seeds that were preconditioned and placed in gel. There was a significant advantage in germination percentage of GA preconditioning at $5{ }^{\circ} \mathrm{C}$ compared to the controls.

\section{Discussion}

Screening gel types for their suitability as seed carriers. Certain gels provide improved conditions for promoting and/or hastening germination under low temperature and under low moisture conditions; these gels could be used as carriers for plant growth regulators (PGRs), antioxidants, antistress compounds and nutrients. The results obtained from these experiments suggest that a synthetic clay gel Laponite RD promoted germination and vigor value both under an ideal temperature of $20^{\circ} \mathrm{C}$ and under a limiting low temperature of $5{ }^{\circ} \mathrm{C}$ (Figs. 1 and 2). Gels such as synthetic clay and guar gum have been used for fluid drilling seeds to hasten seedling emergence in early season crops (Globerson and Feder, 1987; Frinch-savage, 1986). Darby (1980) cited that carrier gels showed improved emergence of a range of crops especially when a synthetic clay gel was used compared to guar gel. These studies, however, were conducted under moisture stress conditions and thus, it is difficult to judge how the gels would have behaved under low temperature and moisture conditions.

Germination was delayed and vigor was reduced in seeds subjected to $5^{\circ} \mathrm{C}$. The reduction in germination at $5^{\circ} \mathrm{C}$ may be due to 1 ) direct effect of temperature; 2) inhibitory effect of gel; 3 ) reduction in water flow from gel to seeds, or 4) a combination of all these factors. The delay in germination observed at $5{ }^{\circ} \mathrm{C}$ might be due to the direct effect of temperature rather than the inhibitory effect of gel since germination and vigor value were the lowest under $5^{\circ} \mathrm{C}$ in the no gel control. Also, if the gel had inhibited germination, then the inhibitory effect should also be evident at $20^{\circ} \mathrm{C}$. Analysis of variance (ANOVA) also indicated that there was no significant interaction between the gels and the concentrations suggesting that the viscosity of the gels may not play a great role in directly influencing seed germination or through its effects on limiting moisture availability. Germination promotion at $20{ }^{\circ} \mathrm{C}$ under gel also supports the idea that the gel may not be directly hindering germination at $5^{\circ} \mathrm{C}$. Low temperature per se could have had a negative effect on germination by limiting moisture availability (Rajasekaran et al., 2004; Rajasekaran et al., 2002). Although there is no direct evidence available, it is also possible that low temperature could have caused a change in

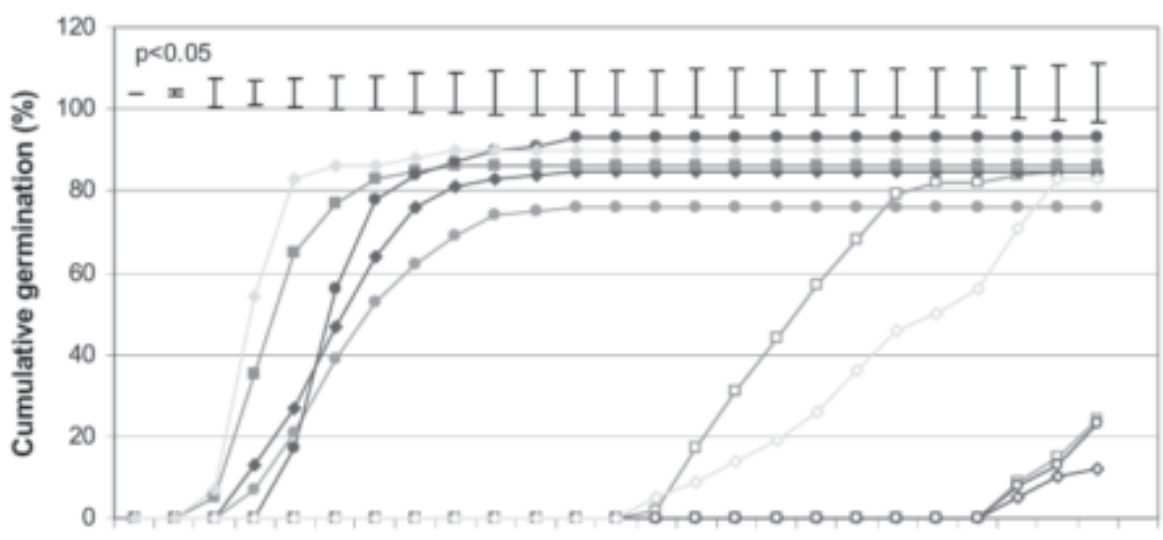

$\begin{array}{lllllllllllllllll}0 & 1 & 2 & 3 & 4 & 5 & 6 & 7 & 8 & 9 & 1011 & 121314 & 15161718192021 & 22 & 23 & 24\end{array}$

\section{Days from seeding}

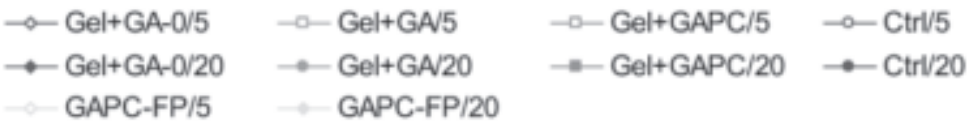

Fig. 5. Cumulative germination of 'Oranza' carrot (Daucus carota L var. sativus) as influenced by GA application methods (preconditioning; gel incorporation) and temperatures $\left(5\right.$ and $\left.20^{\circ} \mathrm{C}\right)$. Bars represent LSD at $P<0.05$. Open symbol represents $5{ }^{\circ} \mathrm{C}$; closed symbol represents $20^{\circ} \mathrm{C}$. Gel $+\mathrm{GA}-0=$ untreated seeds submerged into gel; Gel $+\mathrm{GA}=$ untreated seeds submerged into Gel mixed with $\mathrm{GA}_{3}$; Gel + GAPC $=$ GA-preconditioned seeds submerged into gel; $\mathrm{Ctrl}=$ control, seeds treated with distilled water and submerged into gel; GAPC-FP = GA-preconditioned seeds incubated on Munktell's No. 1 F filter paper in sterile petri dishes.

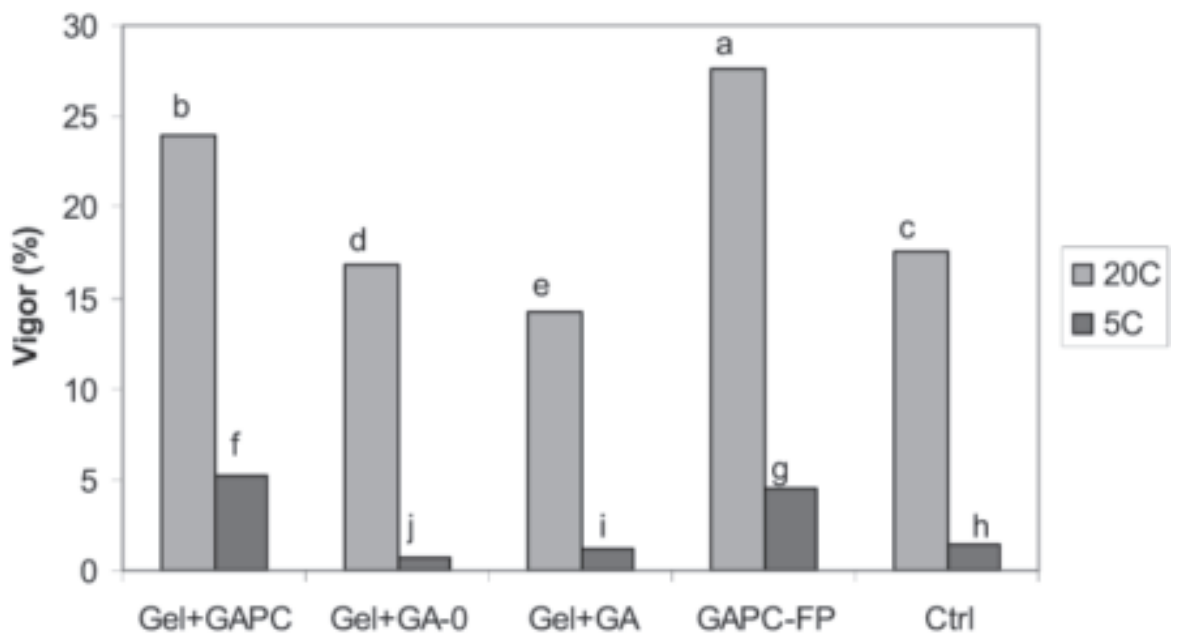

Treatments (application methods)

Fig. 6. Vigor value of 'Oranza' carrot (Daucus carota var. sativus L) s influenced by GA application methods (Preconditioning; Gel incorporation) and temperatures $\left(5\right.$ and $\left.20^{\circ} \mathrm{C}\right)$. Letters that are the same indicate that there is no significant different among the treatments $(P<0.05)$. Gel $+\mathrm{GA}-0=$ untreated seeds submerged into gel only; Gel+GA = untreated seeds submerged into gel mixed with $\mathrm{GA}_{3}$; Gel+GAPC $=$ GA-preconditioned seeds submerged into gel; $\mathrm{Ctrl}=$ control, seeds treated with distilled water and submerged into gel; GAPC-FP = GA-preconditioned seeds incubated on Munktell's No. $1 \mathrm{~F}$ filter paper in sterile petri dishes. 


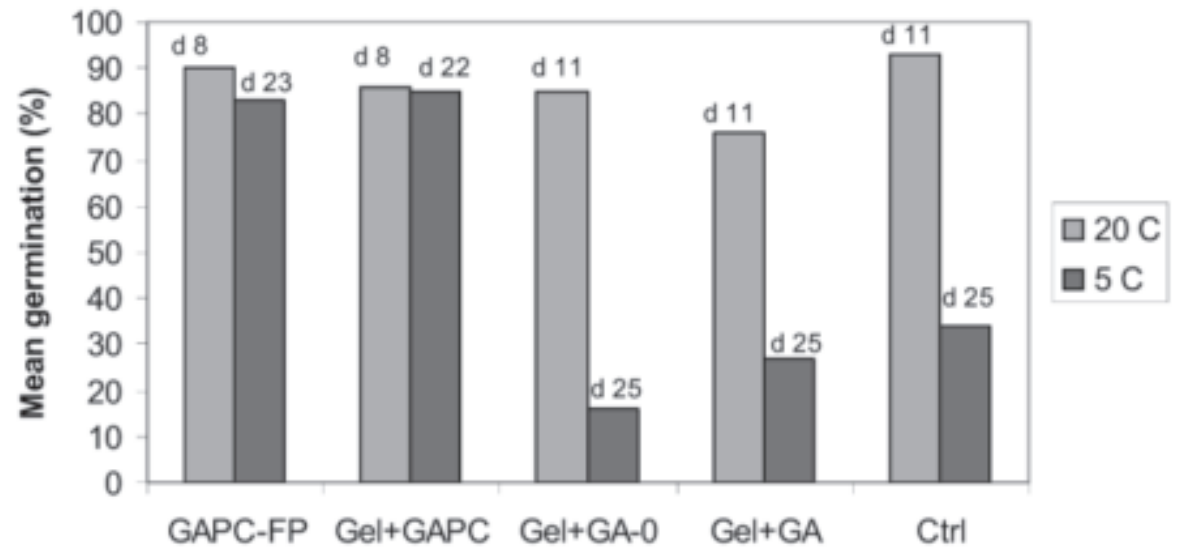

Treatments (application methods)

Fig. 7. Representing the highest mean germination percentage observed in 'Oranza' carrot seeds as influence by GA application methods (Preconditioning; Gel incorporation) and temperatures $\left(5\right.$ and $\left.20^{\circ} \mathrm{C}\right)$. Day 8, day 11, day 22, day 23, and day 25 represents the total number of days over which the highest mean germination percentage was observed. Data obtained from Fig. 5.

of Pinus strobus L. to evaluate media containing various types (agars and gellan gum), brands and concentrations of gelling agents. It is possible that high concentrations of gels increase viscosity which can limit moisture availability (Klimaszewska et al., 2000).

The chemical properties of the gelling agents were not analyzed in this study. However, based on manufacturer's information (Southern Clay Products Inc., Texas) both the synthetic clay gels Laponite RD and Laponite RDS have similar chemical composition. They contain silica oxide $\left(\mathrm{SiO}_{2}\right)$, magnesium oxide $(\mathrm{MgO})$, lithium oxide $\left(\mathrm{Li}_{2} \mathrm{O}\right)$, and sodium oxide $\left(\mathrm{Na}_{2} \mathrm{O}\right)$. The only exception with Laponite RDS was that it contained phosphorus oxide $\left(\mathrm{P}_{2} \mathrm{O}_{5}\right)$. It is not known whether $\mathrm{P}_{2} \mathrm{O}_{5}$ in Laponite RDS inhibited seed germination. However, phosphate concentrations above $30 \mathrm{~g} \cdot \mathrm{L}^{-1}$ have been reported to have a deleterious effect on carrot seedling emergence (Finch-Savage and Cox, 1982). The phosphorus concentration in a $10 \%$ Laponite RDS gel solution (w/v) will be $4.2 \mathrm{~g}$ of phosphorus in a 1-L solution. This means that the phosphorus concentration at which Laponite RDS was mixed is nearly 5 times lower than that of what Finch-Savage and Cox have reported. The $\mathrm{pH}$ of Laponite RD and Laponite RDS is similar, therefore, the inhibitory mechanism in Laponite RDS is unknown.

Agar is the most frequently used agent as a solidifier in plant tissue culture media. It has the desirable characteristics of high gel clarity, stability and resistance to digestion by plant enzymes during use (Puchooa et al., 1999). Agar was also thought to be biologically inert, without active chemical properties. However, a number of studies have shown that agar can have adverse effects including inhibition of growth, presence of impurities and impairment of vitrification (Debergh, 1983; Debergh et al., 1981; Rombergerand Tabor, 1971). It is possible that lack of germination at $5{ }^{\circ} \mathrm{C}$ could be due to the inhibitory effects of the gel itself.

Standardization of GEP delivery system. The results suggest that seed preconditioning with $\mathrm{GA}_{3}$ enhanced germination (Fig. 5) and vigor
(Fig. 6) both at 20 and $5{ }^{\circ} \mathrm{C}$. This is consistent with the results of experiments conducted by Rajasekaran et al. (2004) and Rajasekaran et al. (2002), which indicated that seeds preconditioned using $\mathrm{GA}_{3}$ and salicylates hastened and promoted germination at $5{ }^{\circ} \mathrm{C}$. The delay in germination observed with seeds submerged into Laponite $\mathrm{RD}$ mixed with $\mathrm{GA}_{3}$ at both temperatures could be due to the possibility that $\mathrm{GA}_{3}$ would have bound to the gel, limiting GA availability. Alternatively, GA preconditioning may have hastened and promoted germination through GA's directly triggering alpha-amylase, initiating a cascade of reactions promoting cell division and elongation (Kaneko et al., 2002; Paleg, 1959, 1961). The physiological effects of GA in triggering alpha amylase and promoting germination in monocots have also been demonstrated (Paleg, 1959, 1961) The highest cumulative germination and vigor were observed in seeds that were preconditioned at both temperatures with the exception of the control at $20^{\circ} \mathrm{C}$, which registered $93 \%$ germination (Fig. 7).

According to Rajasekaran et al. (2002), preconditioning promotes temperature acclimation and alters the biochemical composition of seeds, so that seeds can tolerate conditions such as drought and different temperature regimes. Seed preconditioning may perhaps be accelerating physiological and biochemical events through mobilization of the resources within the seed which may further amplify the response through efficient use of external resources hastening germination and emergence. Incubating endosperms in GA has been shown to liberate alpha amylase, sugars, and protein $\mathrm{N}$ (Khan, 1992; Paleg, 1959, 1961). The products of hydrolysis would have provided substrates for rapid cell division and elongation. This could also explain the delay in germination observed with seeds that were impregnated into gel mixed with $\mathrm{GA}_{3}$ since the biochemical and physiological events of those seeds might not have been mobilized as readily as those that were directly preconditioned. Preconditioning methods which include hardening (alternate wetting and drying), chitting (pregermination), osmoconditioning (priming) and matriconditioning have been used to promote germination under limiting conditions such as moisture and temperature in various crops (Khan, 1992). Seed preconditioning using PGR's and bioactive compounds promote germination and provide embryonic seedlings with the ability to cope with adverse environmental conditions (Rajasekaran, 2000; Rajasekaran and Blake, 1998; Rajasekaran et al., 1992). It is possible that the enhancement and promotion of germination especially, at low temperature could be ascribed to the preconditioning effects. The cellular level changes due to GA preconditioning are yet to be fully understood.

\section{Conclusion}

Both at 5 and $20^{\circ} \mathrm{C}$, Laponite RD promoted and enhanced germination and vigor; therefore it is the most suitable carrier for Germination and Emergence Promotors (GEPs) out of all the carriers tested in this experiment.

In experiments conducted to standardized GEP delivery system however, Laponite RD did not provide an additional advantage in promoting germination and vigor at $20{ }^{\circ} \mathrm{C}$ over the controls. At $5{ }^{\circ} \mathrm{C}$ however, submerging GA-preconditioned seeds into gel gave a significant advantage in germination and vigor when compared to the controls. Preconditioning seeds with GA was found to be the most effective method compared to applying GA in to the medium or to the gel directly.

\section{Literature Cited}

Cantliffe, D.J., M. Elballa, and A. Guedes. 1987. Improving stand establishment of direct seeded vegetables in Florida. Proc. Fla. State Hort. Soc. 100:213-216.

Czabator, F. 1962. Germination value: An index combining speed and completeness of pine seed germination. For. Sci. 8:386-96.

Darby, R.J. 1980. Effects of seed carriers on seedling establishment after fluid drilling. Envir. Agr. 16:153-160

Debergh, P. 1983. Effects of agar brand and concentration on the tissue culture medium. Physiol. Plant. 59:270-276.

Debergh, P., Y. Harbaoui, and R. Lemeur. 1981. Mass propagation of globe artichoke(Cynarascolymus): Evaluation of different hypotheses to overcome vitrification with special reference to water potential. Physiol. Plant. 53:181-187.

Finch-Savage, W.E. 1986. The effect of fluid drilling and covering medium on early carrot production under polyethylene mulch. Ann. Appl. Biol. 108:431-439.

Finch-Savage, W. and C.J.Cox. 1982.Effect of adding plant nutrients to the gel carrier use for fluid drilling early carrots. J. Agr. Sci. 99: 295-303.

Globerson, D and Z. Feder. 1987. The effect of seed priming and fluid drilling on germination, emergence and growth of vegetables at unfavorable temperatures. Acta Hort. 198:15-21.

Kaneko,M.,H.Itoh, M. Ueguchi-Tanaka, M.Ashikari, and M. Matsuoka. 2002. The $\alpha$-amylase induction in endosperm during rice seed germination is caused by gibberellin synthesized in epithelium. Plant Physiol. 128:1264-1270.

Khan, A.A. 1992. Preplant physiological seed conditioning. Hort. Rev. 13:131-181.

Klimaszewska, K., M. Bernier-Cardou, D.R.Cyr, and 
B.C.S. Sutton. 2000. Influence of gelling agents on culture medium gel strength, water availability, tissue water potential, and maturation response in embryogenic cultures of Pinus strobus L. In Vitro Cell. Dev. Biol.-Plant 36:279-286.

Paleg, L.G. 1959. Physiological effects of gibberellic acid: I. on carbohydrate metabolism and alpha amylase activity of barley endosperm. Plant Physiol. 35:293-299.

Paleg, L.G. 1961. Physiological effects of gibberellic acid: III. Observations on its mode of action on barley endosperm. Plant Physiol. 35:902-906.

Puchooa, D., P.N. Purseramen, and B.R. Rujbally. 1999. Effects of medium support and gelling agent in the tissue culture of tobacco (Nicotiana tabacum). Res. J. 3:129-144.
Rajasekaran, L.R. 2000. Processing carrot research program. Annu. Rpt. NSAC.

Rajasekaran, L.R. and T. Blake. 1998. Early growth invigoration of jack pine seedlings by natural plant growth regulators. Trees 12:420-423.

Rajasekaran, L.R. and T.J. Blake. 2002. A derivative of 5-hydroxybenzimidazole(Ambiol) promotes growth and acclimates carrot seedlings exposed to drought. Can. J. Plant Sci. 82:195-202.

Rajasekaran, L.R., K.V.V. Ramaru, R. Naidu, and K. Mathews. 1992. Hormonal regulation of seed germination in cardamom(Elettaria cardomomum L. maton). J. Plant Crops 20: 313-317.

Rajasekaran,L.R.,A.Stiles, and C.D. Caldwell. 2002. Stand establishment in processing carrots - Effect of various temperature regimes on germination and the role of salicylates in promoting germination at low temperatures. Can. J. Plant Sci. 82:443-450.

Rajasekaran, L.R.,A. Stiles, M.A. Surette,A.V.Sturz, T.J. Blake, C. Caldwell, and J. Nowak. 2004. Stand Establishment Technologies in Processing Carrots. Acta Hort. 631:105-116.

Romberger, J.A. and C.A. Tabor. 1971. The Picea abies shoot meristem in culture. I:Agar and autoclaving effects. Amer. J. Bot. 58:131-140.

Simatos, D., M. Facure, E. Bonjour, and M. Couach. 1975. The physiological state of water at low temperature in plasma with different water contents as studied by differential thermal analysis and differential scanning calorimeter. Cryobiology 12:202-208. 